\section{Allergic rhinitis and school performance}

\author{
*Alan Kaplan \\ Chair, Family Physician Airways Group of Canada \\ *Tel: +1 9058831100 \\ E-mail: for4kids@gmail.com
}

\begin{abstract}
Walker S et al. Seasonal allergic rhinitis is associated with a detrimental effect on examination performance in United Kingdom teenagers: case control study. J Allergy Clin Immunol 2007;120(2):381-7
\end{abstract}

Does it matter if we treat allergic rhinitis? This study reviewed the effect of allergic rhinitis on school performance. Previous studies have investigated the effects of allergic rhinitis on learning ability by using computer simulation in a classroom situation; they showed significant learning impairment in children with symptomatic allergic rhinitis compared with asymptomatic control subjects, ${ }^{1}$ effects that were compounded by sedating antihistamines. ${ }^{2}$ This study by Walker et al looked at the effect of seasonal allergic rhinitis on actual examination performance in teenagers. The allergy season was considered to be the six-week period from mid-May to the end of June when grass pollen counts are at their highest. ${ }^{3}$

Methods: Case-control analysis of 1834 students (age 15-17 years; $50 \%$ girls) sitting for national examinations in Britain. Cases were those who dropped one or more grades in any of three core subjects (mathematics, English, and science) between practice (winter) and final (summer) examinations. Controls were those whose grades were either unchanged or improved. Associations between allergic rhinitis symptoms, clinician-diagnosed allergic rhinitis, and allergic rhinitis-related medication use, recorded on examination days immediately before the examination, were assessed using multilevel regression models.

Results: Between 38\% and $43 \%$ of students reported symptoms of seasonal allergic rhinitis on any one of the examination days. There were 662 cases (36\% of students) and 1172 controls. After adjustment, cases were significantly more likely than controls to have had allergic rhinitis symptoms during the examination period (odds ratio [OR], 1.4; $95 \% \mathrm{Cl}, 1.1-1.8 ; \mathrm{P}$ value .002), to have taken any allergic rhinitis medication (OR, 1.4; $95 \% \mathrm{Cl}, 1.1-1.7$; $\mathrm{P}$ value .01), or to have taken sedating antihistamines $(\mathrm{OR}, 1.7 ; 95 \% \mathrm{Cl}, 1.1$ 2.8; $P$ value .03).
Authors' conclusion: Current symptomatic allergic rhinitis and rhinitis medication use are associated with a significantly increased risk of unexpectedly dropping a grade in summer examinations. This shows the relationship between symptomatic allergic rhinitis and poor examination performance.

\section{Comment}

The methodology here is interesting. Clearly we know that allergic rhinitis influences quality of life and asthma control. ${ }^{4}$ We know also that obstructive sleep apnoea affects wakefulness and performance, even in children. Allergic rhinitis can cause effects that are subtle and may not be obvious, but which could have significant future implications on our children through school performance. Children, especially at the end of high school, must begin to make life choices, and their marks may permit or prevent these life choices.

International guidelines (ARIA ${ }^{4}$, IPCRG ${ }^{5}$ ) have reviewed the management of allergic rhinitis. The first step in treatment is identification of the allergen and allergen avoidance. An interesting editorial in this journal in $2006^{6}$ discussed empiric treatment without the need for skin testing, suggesting that skin testing should be reserved for diagnostic uncertainty, failure of allergen avoidance techniques, or for those patients with a convincing history of eczema, rhinitis and asthma in whom aeroallergen-triggered disease is suspected and in whom treatment with specific immunotherapy is being considered. On the other hand, skin testing can be performed safely by primary care practitioners, and allergens can also be sought by specific serological lgE testing ${ }^{7,8}$ (such as IM MUNOCAP). Pharmacotherapy with antihistamines, nasal ICS, nasal chromones, and leukotriene receptor antagonists all have their place. Surgical management of comorbidities such as septal deviation and polyps can also be helpful.

The bottom line is that we should pay attention to those children and adolescents with runny noses...

\section{References}

1. Vuurman EPF, van Veggel LMA, Uiterwijk MMC, Leutner D, O'Hanlon JF. Seasonal allergic rhinitis and anti-histamine effects on children's learning. Ann Allergy 1993;71:121-6.

2. Vuurman EPF, van Veggel LMA, Sanders RL, Muntjewerff ND, O'Hanlon JF. Effects of semprex-D and diphenhydramine on learning in young adults with seasonal allergic rhinitis. Ann Allergy Asthma Immunol 1996;76:247-52.

3. Emberlin J, Mullins J, Corden J, et al. Regional variations in grass pollen seasons in the UK, long-term trends and forecast models. Clin Exp Allergy 1999; 29:347-56. 
4. Bousquet J, Van Cauwenberge PB, Khaltaev N. Allergic Dhinitis and its Impact on Asthma (ARIA) in collaboration with the World Health Organisation (WHO). J Allergy Clin Immunol 2001;108:S147-336.

5. Price D, Bond C, Bouchard J, et al. International Primary Care Respiratory Group (IPCRG) Guidelines: Management of Allergic Rhinitis. Prim Care Resp J 2006; 15(1):58-70. doi:10.1016/j.pcrj.2005.11.002

6. Walker S, Morton C, Sheikh A. Diagnosing allergy in primary care: are the history and clinical examination sufficient? Prim Care Resp J 2006;15(3):21921. doi:10.1016/j.pcrj.2006.05.008
7. Ahlstedt S, Murray CS. In vitro diagnosis of allergy: how to interpret IgE antibody results in clinical practice. Prim Care Resp J 2006;15(3):228-36. doi:10.1016/j.pcrj.2006.05.004

8. Williams PB, Dolen WK, Koepke JW, Selner JC. Comparison of skin testing and three in vitro assays for specific $\lg E$ in the clinical evaluation of immediate hypersensitivity. Ann Allergy 1992;68:35-45.

doi:10.3132/pcrj.2008.00010

\section{Available online at http://w ww.thepcrj.org}

